\title{
Solar-driven Refrigerator for off-grid Regions
}

\author{
Jakub Kuś ${ }^{1}$, Kyrylo Rudykh ${ }^{1}$, Marcin Kobas $^{1}$, Maciej Żołądek ${ }^{1, *}$, Szymon Sendłak ${ }^{1}$, Maciej Gumułka ${ }^{1}$, Krzysztof Sornek $^{l}$ \\ ${ }^{1}$ AGH University of Science and Technology, Faculty of Energy and Fuels, Department of Sustainable Energy \\ Development, Krakow, Poland
}

\begin{abstract}
Refrigeration systems are necessary for people living in hot climates. A majority of tropical and subtropical countries uses electrical power as a source of cooling. During the seasons of high ambient temperature there is a significant cooling load due to increased level of energy consumption. Cooling systems are therefore necessary in African countries in order to keep medications and food in safe conditions. Furthermore, there is a power shortage crisis due to the high demand for cooling. TRNSYS software allows to simulate a complete solar-powered absorption cooling system. A model used in an experiment includes PV modules making it advantageous over a conventional cooling system. PV modules of assumed area are sufficient to maintain the temperature inside cooling device below $6^{\circ} \mathrm{C}$ over the whole year.
\end{abstract}

\section{Introduction}

\subsection{Solar Systems for domestic cooling meet the increasing demand for air conditioning}

Energy consumed for domestic cooling and airconditioning constitutes significant share in energy demand of the buildings. Since the buildings are responsible for approximately $40 \%$ of the global energy consumption [1], situation on the energy market is noticeably affected by requirement for cooling and air-conditioning [1]. Studies have shown a rapid increase in the air-conditioning market around the world and predict further development. Additionally, capability of passive cooling has been restrained by global warming [2]. Those factors contribute to increasing amount of energy consumed for the purpose of cooling and air-conditioning worldwide. In order to meet progressively more restrictive environmental goals established among the international community, i.e. reduction of primary energy consumption and greenhouse gases emission, a wide range of systems for cooling and airconditioning based on renewable or waste energy has been proposed. One of the most suitable option among other renewable energy sources is solar energy, as top airconditioning demand overlaps with the highest solar irradiance [3].

Compared to cooling systems powered solely by the public power grid, solar-driven systems are seen as more environment-friendly alternative [4]. These are able to utilize solar energy and therefore to lower the primary energy consumption. It is estimated that deployment of solar cooling systems in southern European and Mediterranean regions could lead to $40-50 \%$ savings of primary energy [5]. Introduction of solar cooling systems also allows to avoid some drawbacks of the regular grid- powered vapour compression-based machines. Classic VC machines significantly burden the grid over the periods of greatest cooling demand, whereas solar cooling systems diminish grid peak load $[1,6]$. That feature is considered as convenient particularly during summers when the largest demand for cooling occurs [7]. Such a coincidence between cooling demand and availability of solar energy is the reason why solar cooling is a raising technology, arguably with greater potential than solar domestic heating [8].

Several studies indicate that deployment of solar cooling could be particularly suitable in tropical or subtropical areas [5]. Solar-based cooling systems are identified as promising technology in some regions of Asia, especially in the countries geographically aligned with equator as they take advantage of abundant solar energy [9].

\subsection{Development of multifunctional solar cooling systems}

It is reported that solar cooling systems are almost always multifunctional and are used not only for cooling but also for supplying hot water and domestic heating off-season $[5,10]$. That feature makes solar cooling more profitable [1]. Nu mber of reported solar cooling system installed worldwide is around 1200 (as for 2014) and is expected to increase due to quick development of solar cooling technology [1]. Taking into account that usually solar cooling systems are also heating systems, from now on they will be referred to as solar heating and cooling systems (SHC).

Given that multiple solar technologies are available, SHC systems differ in utilised method of harvesting solar energy which may be obtained with

* Corresponding author: mzoladek@agh.edu.pl 
photovoltaic solar panels or with solar thermal collectors [7]. Further classification of SHC systems is based on distinction if the cooling effect is provided with electrically-driven or thermally-driven process [1, 7]. Electrically-driven cooling is usually achieved by utilising vapour compression cycle and/or heat pumps [7]. Thermally-driven cooling technologies include absorption and adsorption chillers, ejector cycles as well as solid/liquid desiccant cycles $[1,5,7$ 11]. Thermally-driven cooling requires heat source and thus could be realised either with PV solar panels or solar thermal collectors. As the main interest of the article is absorption cooling technology, it will be discussed more specifically to the extent necessary later on. Amongst listed SHC layouts the most popular one includes thermally-d riven chiller and solar thermal collector combined with a thermal storage system [7].

The main obstacle restraining development of SHC is high capital cost of those installations. If reasonable economic profitability is to be achieved, high capital cost must be balanced with low operating cost [7]. The payback period depends on a wide range of factors such as utilised components, geographic conditions and government subsidies [10]. As mentioned earlier, profitability could be increased by designing multifunctional SHC systems. The payback period of all types of solar cooling systems falls within the range of 7.6-11.4 years [1], while in case of coupling solar cooling with heating (SHC), payback period is evaluated to be in the range of 3-15 years [10]. PV-based SHC systems face additional barrier restraining their development, e.g. high price of battery storage required for continuous operation of the system over the periods of scarce solar energy. On the other hand, capital cost of photovoltaic solar panels is decreasing and that trend contributes to more favourable financial metrics [1].

Cooling with absorption chillers is well-established technology that has been widely used in air-conditioning but up till now absorption cycles have been driven mainly with natural gas or industrial waste heat [1]. Studies indicate that currently large-scale SHC absorption chillers are not competitive compared to conventional cooling, leaving aside government subsidies [1,9]. That applies especially to the buildings with limited area exposed to solar radiation. Nevertheless, SHC absorption chillers are expected to become a promising solution in addressing environmental issues [9] but special attention must be paid to improving their economical performance [1]. Among various SHC systems, absorption chillers technology is the most developed commercially [5] and therefore considered to compete with conventional air-conditioning in foreseeable future [1].

\subsection{Solar absorption chillers}

Most common SHC systems shall consist of absorption chiller combined with solar thermal collectors and thermal storage system [7] For reference, about 59\% of SHC in Europe were based on absorption cooling technology in 2007 [5]. In research particular attention has been paid to the systems based on single-effect chillers coupled with low-temperature solar thermal collectors [1] and such attention corresponds to the most popular layout of solar absorption chillers worldwide [10]. Subject of using high-temperature solar thermal collectors and multieffect chillers in SHC gained less attention [1] and generally those systems are less widespread among the world. From that overview the following picture of the regular SHC system emerges: such a system is based on thermally-driven single-effect absorption cooling cycle and consists of four basic components, namely an absorption chiller combined with a (lowtemperature) solar thermal collector, a storage tank and an auxiliary heater. That typical system is usually multifunctional as it serves also for domestic heating and/or hot water production.

In comparison to conventional vapour compression chillers, absorption chiller is a device featuring such advantages as: quiet and low-vibration operation, little maintenance and environmentalfriendly functioning [1, 11]. Additionally, device realises cycle in which pressure of medium in liquid state is to be increased and that could be done economically with a pump as opposed to a situation occurring in vapour compression cycle when a compressor must be applied to increase pressure of medium in gaseous state. Therefore absorption chiller requires little mechanical energy input [1]. In comparis on to other SHC systems, absorption chillers achieve higher COP than adsorption chillers [7].

\subsection{Solar absorption chillers operating on $\mathrm{NH} 3-\mathrm{H}_{2} \mathrm{O}$ mixture}

Performance of absorption chiller (AC) depends on properties of operating mixture consisting of refrigerant and absorbent. Two fluids must comply with a wide range of requirements. Their liquid phases must be miscible in all temperatures reached in cooling cycle [1]. In such a range of temperature, fluids and their mixture should be chemically stable, non-toxic and non-explosive. $[1,12]$. Another favourable property is possibly large difference between the boiling points of mixture and pure refrigerant [12]. Otherwise applying dephlegmator may be needed [1]. High heat of vaporization and capacity to reach high concentration within the absorbent is also considered as advantageous refrigerant property since it allows to realise cooling process with low circulation rate [12]. While reaching high concentration of refrigerant in absorbent is beneficial, increasing ammonia initial concentration in mixture could decrease mass transfer rate and even stop the absorption process for ammonia initial concentration of about $60 \%$ [8]. Non-corrosive, inexpensive and safe for environment fluid pairs are preferred [12]. Refrigerant should be volatile in order to enable easy separation in generator [1], while absorbent ought to be non-volatile so rectification of absorbent will not be necessary after desorption [13].

Most prevalently used refrigerant-absorbent pairs are $\mathrm{H}_{2} \mathrm{O}-\mathrm{LiBr}$ and $\mathrm{NH}_{3}-\mathrm{H}_{2} \mathrm{O}$ [1]. As ammonia freezing point in considered range of pressure is equal to $-77^{\circ} \mathrm{C}$, ACs utilising $\mathrm{NH}_{3}-\mathrm{H}_{2} \mathrm{O}$ are able to produce cooling 
temperature below $0^{\circ} \mathrm{C}$ [12] but they need higher temperatures in generators than $\mathrm{H}_{2} \mathrm{O}-\mathrm{LiBr}$-based machines [1]. They also achieve lower COP [1] in a range of 0.5-0.6 [6], while corresponding values for $\mathrm{H}_{2} \mathrm{O}-\mathrm{LiBr}$ are $0.7-0.8$. Due to their capability to achieve temperatures below $0^{\circ} \mathrm{C}$, $\mathrm{NH}_{3}-\mathrm{H}_{2} \mathrm{O}$ A Cs are preferred for cooling, while $\mathrm{H}_{2} \mathrm{O}-\mathrm{LiBr}$ ACs for air-conditioning [1]. $\mathrm{H}_{2} \mathrm{O}-\mathrm{LiBr}$ displays some corrosive properties thus addition of anti-corrosives is required [6].

Despite slightly lower COP and higher driving temperature required in case of $\mathrm{NH}_{3}-\mathrm{H}_{2} \mathrm{O}$ ACs, they are free of some construction constraints present for $\mathrm{H}_{2} \mathrm{O}-\mathrm{LiBr} \mathrm{ACs}$. The second fluid pair cannot operate in temperatures lower than $0^{\circ} \mathrm{C}$ due to water being refrigerant which freezes in such temperature but also temperature of $40^{\circ} \mathrm{C}$ cannot be exceeded because the possibility of $\mathrm{LiBr}$ crystallisation from mixture occurs as the saturation point is achieved [3]. Crystallisation could also occur when solution rich in $\mathrm{LiBr}$ salt has high concentration. Crystallisation may lead to blocking of the pipes and valves [1] therefore operational temperature range is restrained and that could limit utilisation of $\mathrm{H}_{2} \mathrm{O}-\mathrm{LiBr} \mathrm{ACs}$ in extre me weather conditions [1]. When it comes to physical size of the system, $\mathrm{H}_{2} \mathrm{O}-$ $\mathrm{LiBr}$ ACs are generally larger than their $\mathrm{NH}_{3}-\mathrm{H}_{2} \mathrm{O}$ counterparts, because vapour volume of refrigerant is significantly larger [6]. Since the difference between the boiling temperature of ammonia and water is not very high, $\mathrm{NH}_{3}-\mathrm{H}_{2} \mathrm{O}$ absorption chillers also need a dephlegmator to separate ammonia and water vapour inside the generator [1].

\subsection{Multiple-effect cycles for solar absorption chillers}

Another critical parameter affecting performance of ACs is number of times heat has been recycled before completing the loop. Single-, double- and triple-effect (alternatively: single-, double-, triple-stage) ACs could be listed as commercially available [1]. Number of effects corresponds to number of generators in which heat flow is harvested to realise the process of desorption. Higher COP could be achieved with increasing number of cycles but that operation requires higher temperatures for every further cycle [1].

It is reported that in regions characterised by low solar resources, solar multi-effect chillers are relatively inefficient thus single-effect is preferred choice [1]. Singleeffect ACs' COP is limited to around 0.7 [13] and they require driving temperature of $80-100^{\circ} \mathrm{C}$ ( $\left.\mathrm{LiBr}\right)$ [13]. In order to raise COP of single-effect ACs, solution heat exchangers are applied for preheating solution entering the generator with heat received from water returning to absorber [1].

Double-effect ACs utilise additional generator and operate between different pressure levels. They achieve higher COPs (up to 1.4) but require higher driving temperature [1]. Starting with double-stage chillers, generators could be connected in different ways through series, parallel and reverse-series flow cycles [1] displaying non-obvious dependence between layout structure and performance of a chiller [1]. Currently all commercially available double-effect ACs operate on $\mathrm{H}_{2} \mathrm{O}-\mathrm{LiBr}$ cycle since $\mathrm{NH}_{3}-\mathrm{H}_{2} \mathrm{O}$ requires higher pressure.

Studies have shown that variable effect (1.n-effect) absorption cycles are under development. Such systems allow vapour to undergo either single- or double-effect cycle and ratio of both vapour volumes subjected to those cycles is regulated by generators temperatures [10]. As no specific components differ 1.n-effect cycle from single-effect cycle, [10] it could easily extend a range of ACs utilisation.

Three-effect configuration rarely occurs because driving temperature must be higher than in case of single- and double-effect ACs. There are some hybrid configurations in which single-effect cycle powered with solar thermal energy is used accompanied by double-stage gas-fired cycle. Those different methods could work independently or simultaneously [10].

\section{Analyses}

\subsection{Energy sources}

The analyses were undertaken for Ouagadougou which is the capital of Burkina Faso. Burkina Faso is an African country classified as one of the Third World Countries. Its electrification rate is estimated to be around $20 \%$, meaning that more than 12.1 million people do not have access to the electricity [14]. The solar-powered absorption refrigerator facilities could improve healthcare in power-deprived regions. Annual solar irradiance in Burkina Faso is equal to $19.8 \mathrm{MJ} / \mathrm{m}^{2}$ per day and direct sunshine is available over 3000 hours per year [15].

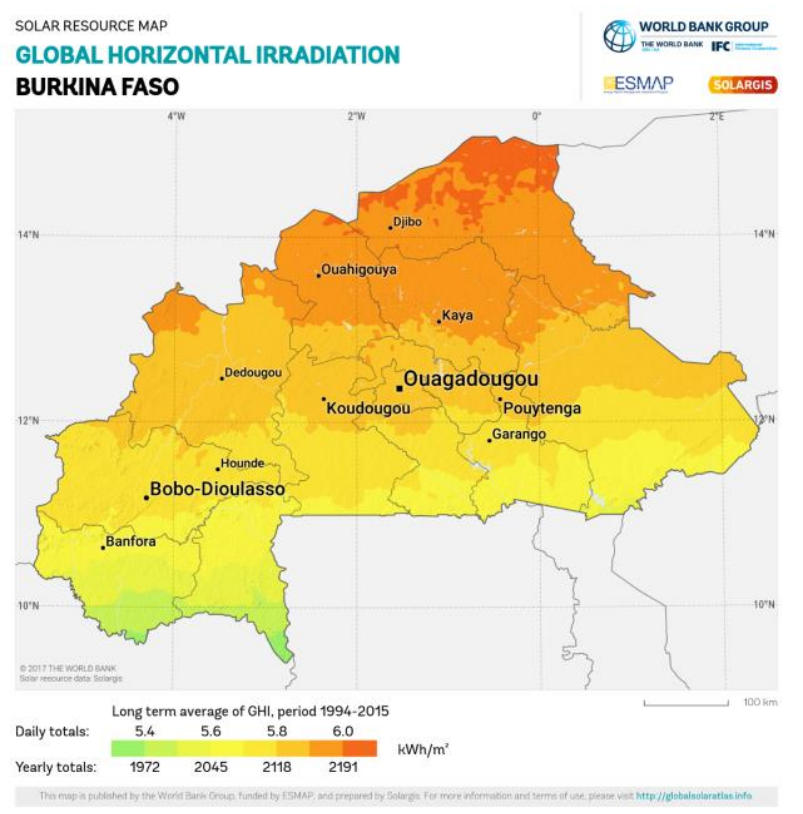

Fig 1. Solar power potential in Burkina Faso [16]

Fig 1. shows the map with average annual solar irradiance in the country. Annual mean global irradiation in Burkina Faso falls within the range of 5.4-6.0 $\mathrm{kWh} / \mathrm{m}^{2}$, providing suitable conditions for use of photovoltaics. Solar refrigeration system could 
become inexpensive and environment-friendly source of cooling for storage facilities. This paper describes an offgrid cold storage system which is able to keep medications cool for a long time. This installation may be cut off from external electrical network and powered with local sources of renewable energy.

\subsection{Solar-powered absorption refrigeration cycle with circulation based on convection}

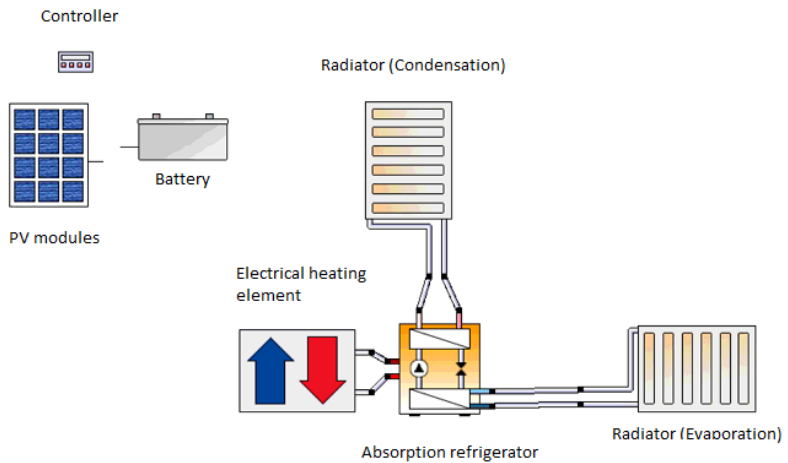

Fig. 2. Schematic diagram of a solar-powered absorption refrigerator system

The main elements of cooling system are shown in Fig. 2 as following: PV modules, absorption refrigerator, two heat exchangers e.g. evaporator and condenser, battery storage, electrical heating element and the control system. The incident solar radiation is converted to electric current by three PV modules of combined power equal to $480 \mathrm{~W}$. After regulating its electrical parameters the current is supplied to connected $12 \mathrm{~V}$ battery with capacity of $200 \mathrm{Ah}$ and to electrical heating element. Control system switches power supply to heating element if the temperature of working mixture $\left(\mathrm{NH}_{3}-\mathrm{H}_{2} \mathrm{O}\right)$ is lower than $80^{\circ} \mathrm{C}$ or to the battery if this temperature is achieved. Ammonia absorption refrigerator produces cooling effect in order to maintain the low temperature in analysed $90 \mathrm{dm}^{3}$ tank by boiling working mixture and forcing its circulation. Condensation, the subsequent step in the cooling process, is realised by rejection of latent heat to the ambient. The refrigerant enters the evaporator as a low-quality saturated mixture, and it completely evaporates by absorbing heat from the refrigerated space. All the flows in refrigerator are based on convection, caused by changes of density. Therefore in presented system electrical heating element is the only device consuming considerable amount of energy. COP of the analysed installation was calculated as a 0.55 which value is much lower than COP of systems based on vapour compression which is at the level of 3.5. There is a risk of ammonia leakage which is toxic to people but it is minimized by tight seal of the system.

\subsection{System simulation}

Some critical parameters of the system were summarized in Table 1.
Table 1. System key parameters

\begin{tabular}{|c|c|}
\hline Description & Specification \\
\hline Volume & $90 \mathrm{dm}^{3}$ \\
\hline Cooling set point & $2-6^{\circ} \mathrm{C}$ \\
\hline Operation hours & Continuous \\
\hline Solar fraction & $100 \%$ \\
\hline PV panels power & $480 \mathrm{~W}$ \\
\hline Electrical heater power & $250 \mathrm{~W}$ \\
\hline COP & 0.55 \\
\hline Weather data & Ouagadougou, Burkina \\
& Faso \\
\hline
\end{tabular}

Figure 3 shows solar panels' energy output in following time steps, depending on irradiation of the area. Simu lation shows that the average annual energy production ensures work of solar refrigerator system cut off from external electrical network.

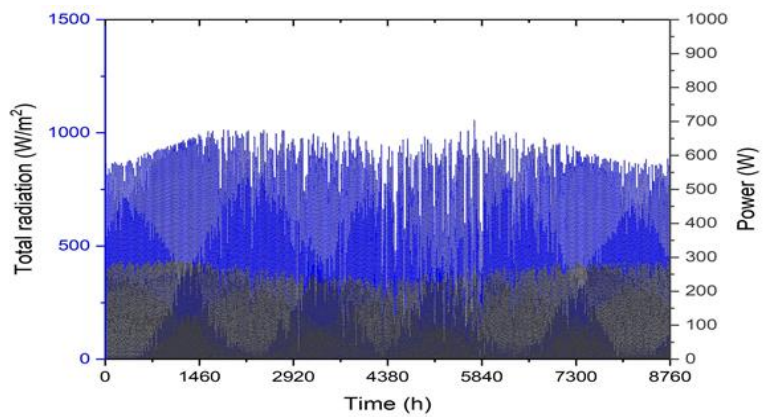

Fig. 3. PV panels power output depending on the received irradiation

The results were obtained through TRNSYS simulation which was run with 6 minutes time step. The analysed system has successfully maintained storage temperature below the point of $6^{\circ} \mathrm{C}$, even while the a mbient temperature was over $40^{\circ} \mathrm{C}$ during the peak of summer season (Fig. 4).

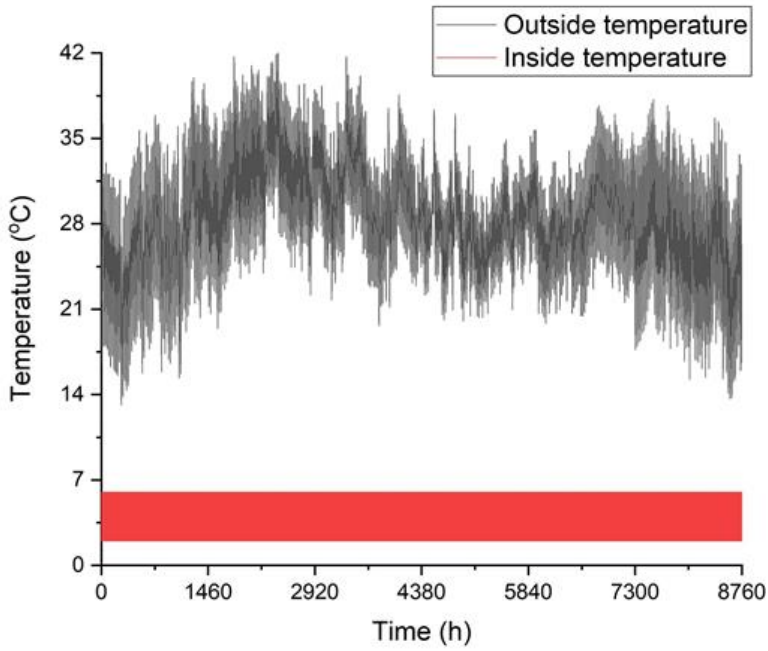

Fig. 4. Simulated internal temperature and ambient temperature over the period of one year

\section{Conclusions}


The considered cooling appliance powered by three PV modules with nominal power of $480 \mathrm{~W}$ is sufficient to accumulate energy for continuous cooling and keeping medications in safe conditions off-grid. It is possible to maintain the temperature within the range of $2-6^{\circ} \mathrm{C}$ regardless of the season. Absorption cooling system has wide range of applications in many branches of industry. Africa's climate shall provide huge potential for use of solar-powered cooling systems. Considering the profitability of analysed device, proposed system allows to save 2.19 MWh per year, which corresponds to about $280 €$. Construction of the device costs more or less $1500 €$, which means that SPBT (simple payback time) is below 5.5 years. Lifetime of the installation is limited by lifetime of the battery storage, which is declared by the producer to be around 10 years. There are possibilities of upgrading the system, for example with the use of solar tracking for PV modules and accumulation of heat in PCM or water tank.

\section{Acknowledge}

This work was financially supported by the Statutory Grant of the Faculty of Energy and Fuels at AGH University of Science and Technology and grant of the Polish Ministry of Higher Education "Best of the Best! 3.0". The equipment of Center of Energy (Czarnowiejska 36, 30-054, Krakow, Poland) was used.

\section{References}

1. Shirazi A., Taylor R.A., Morrison G.L., Stephen D., Energy Conversion and Management 171 (2018) 59-81

2. Arabkoohsar A., Andresen G.B., Energy Conversion and Management 148 (2017) 184-196

3. S. A. M. Said, K. Spindler, M. A. El-Shaarawi, M. U. Siddiqui, Design, International Journal of Refrigeration 62 (2016) 222-231
4. Neyer D., Osheimer M., Hauer N., Halmd ienst C., Pink W. Solar Energy 173, (2018) 715-727

5. Zhai X.Q., Qu M., Li Y., Wang R.Z., Renewable and Sustainable Energy Reviews 15 (2011) 44164423

6. Ghafoor A., Munir A., Renewable and Sustainable Energy Reviews 43, (2015) 763-774

7. Buonomano A, Calise F., Palombo A., Renewable and Sustainable Energy Reviews 82, (2018), 1874-1908

8. Lostec B.L., Galanis N., Millette J., International Journal of Refrigeration 35, (2018) ; 2275-2286

9. Lubis A., Jeong J., Saito K, Giannetti N., Renewable Energy 99 (2016) 825-835

10. Ge T. S., Wang, R. Z.. Xu, Y, Pan Q. W., Renewable Energy 126 (2018) 1126-1140

11. Lostec B.L., Galanis N., Millette J., Renewable Energy 60 (2013), 269-283

12. Sun J., Fu L., Zhang S, Renewable and Sustainable Energy Reviews 16 (2012) 18991906

13. Shirazi A, Taylor R.A., White S.D., Graham L. Morrison, Energy Conversion and Management 114 (2016) 258-277

14. https://www.cia.gov/library/publications/theworld-factbook/geos/uv.html

15. https://www.lightingafrica.org/country/burkinafaso/

16. https://globalsolaratlas.info/downloads/burkina$\underline{\text { faso }}$ 